\title{
AS FRONTEIRAS PSI-JURÍDICAS EM DECISÕES JUDICIAIS SOBRE O “CRIME” E O "CRIMINOSO"
}

\author{
Marília de Nardin Budó ${ }^{1}$
}

\begin{abstract}
Resumo: Este trabalho traz as principais reflexões propostas no Minicurso de mesmo título, realizado durante o Encontro Catarinense de Saúde Mental. O minicurso teve como objetivo abordar as interfaces entre os campos do direito e da Saúde Mental, especificamente no que tange à construção social da noção de "perigo" atribuída a pessoas submetidas à lei penal manifesta ou latente, buscando compreender as formas como o discurso psi tem sido apropriada no discurso judicial. Para tanto, trabalhamos com algumas decisões judiciais nos temas das medidas de segurança e medidas socioeducativas.
\end{abstract}

Palavras-chave: periculosidade, medidas de segurança, medidas socioeducativas, ato infracional.

\begin{abstract}
This work brings the main reflections proposed in the Minicourse of the same title, held during the Santa Catarina Meeting of Mental Health. The short course aimed to address the interfaces between the fields of law and Mental Health, specifically with regard to the social construction of the notion of "danger" attributed to people subjected to overt or latent criminal law, seeking to understand the ways in which the psi discourse has been appropriate in judicial discourse. To do so, we work with some court decisions on the topics of security measures and socio-educational measures.
\end{abstract}

Keywords: dangerousness; security measures; socioeducational measures; infractional act.

Introdução

Este trabalho traz as principais reflexões propostas no Minicurso de mesmo título, no Encontro Catarinense de Saúde Mental. O minicurso teve como objetivo abordar as interfaces entre os campos do direito e da Saúde Mental, especificamente no que tange à construção social da noção de "perigo" atribuída a pessoas submetidas à lei penal manifesta ou latente, buscando compreender as formas como o discurso psi tem sido apropriado no discurso judicial. Partindo de trabalhos anteriores, que resultaram em três publicações, analisamos os conceitos de culpabilidade, inimputabilidade, periculosidade e vulnerabilidade a partir de análises de decisões judiciais sobre: a avaliação da "periculosidade" do agente que cumpre medida de internação em hospital de custódia; a psiquiatrização das medidas socioeducativas e a superação da expressão

\footnotetext{
1 Professora adjunta no departamento de direito da Universidade Federal de Santa Catarina. E-mail: mariliadb@yahoo.com.br
} 
"periculosidade" para dar lugar ao uso da expressão "vulnerabilidade" de adolescentes que cumprem medida socioeducativa de internação.

\section{Culpabilidade, inimputabilidade e periculosidade: categorias de base}

A legislação penal brasileira está baseada em um fundamento político de uma suposta legitimidade do exercício do poder de punir do Estado sobre aquelas pessoas que utilizam seu livre-arbítrio para praticarem condutas violadoras de normas penais, de forma ilícita. Em virtude dessa escolha, que se presume racional, a punição aparece na forma de uma responsabilização, com finalidades retributivas e preventivas. Essa seria uma descrição, ainda que simplificada, do princípio de culpabilidade no direito penal, formulada na perspectiva clássica da reforma penal de base iluminista do século XVIII na Europa. No discurso produzido pelos juristas intelectuais da classe burguesa em luta contra o arbítrio punitivo do Estado, o princípio de culpabilidade aparece como fundamento da imposição da pena estatal, pressupondo uma limitação ao poder de punir (FOUCAULT, 2009).

Porém, um dos problemas do foco no livre-arbítrio que fundamentaria a culpabilidade e, portanto, uma imposição de pena, é a sua indemonstrabilidade e a generalidade, sendo que numerosos autores têm buscado rechaçar a culpabilidade para encontrar critérios de imputação mais racionais, apropriados e exatos (ROXIN, 2007). Da mesma forma, do ponto de vista da criminologia crítica, a crítica da culpabilidade parte do seu pressuposto consensualista, desconsiderando as opressões estruturais e as diferenças, que demarcam limites à liberdade. Daí a crítica pertinente de que o princípio de culpabilidade deve servir como limitação da pena, para garantir a liberdade do cidadão contra o poder do Estado, ao contrário de fundamentar a pena e legitimar o poder do Estado contra o indivíduo (SANTOS, 2008). Nesse sentido, "a culpabilidade nunca exige uma pena; somente sua ausência exclui a pena e sua magnitude determina a fronteira máxima da pena" (SANTOS, 2008, p. 288).

Em seu conceito normativo, a culpabilidade é compreendida como reprovabilidade. O juízo de reprovação é possibilitado através da análise de três categorias: a imputabilidade, entendida como "condições pessoais mínimas que capacitam o sujeito a saber o que faz"; a consciência da antijuridicidade, "como conhecimento concreto do valor que permite ao autor imputável saber, realmente, o que faz"; e a exigibilidade de conduta diversa, "como expressão de normalidade das circunstâncias de fato e indicação de que o 
autor tinha o poder de não fazer o que fez (SANTOS, 2008, p. 282)".

A categoria dos inimputáveis surge como forma de limitar a punição estatal àqueles e àquelas que tiveram condições de, na prática de sua conduta, entender o caráter ilícito do fato e se autodeterminar de acordo com esse entendimento. Por isso, no art. 26 do Código Penal, os "doentes mentais" são considerados inimputáveis e, portanto, irresponsáveis penalmente, pois "para que se possa reprovar uma conduta a seu autor, é necessário que ele tenha agido com um certo grau de capacidade, que lhe haja permitido dispor de um âmbito de autodeterminação" (ZAFFARONI et al., 2008, p. 535).

Também se enquadram na categoria de inimputáveis os menores de 18 anos. 0 art. 27 do Código Penal, corroborado pelo art. 228 da CF e pelo art. 104 do Estatuto da Criança e do Adolescente, define que os inimputáveis pela menoridade não podem ser responsabilizados criminalmente, mas ficam submetidos à legislação específica. Trata-se do reconhecimento, conforme a própria normativa internacional, de que pessoas com menos de dezoito anos são pessoas em desenvolvimento e assim devem ser compreendidas $^{2}$.

Embora a inimputabilidade em ambos os casos seja uma causa de exclusão da culpabilidade - que é o fundamento do poder de punir do Estado -, quando comprovada a ocorrência do fato, a sua autoria, e a ilicitude da conduta, a legislação penal prevê a possibilidade de intervenção estatal sobre os autores. Essa intervenção não é considerada, de forma manifesta, uma punição, mas sim uma medida. No caso dos adolescentes até 18 anos, a resposta do Estado ocorre na forma de uma medida socioeducativa, nos termos do Estatuto da Criança e do Adolescente. Segundo o Estatuto, dentre as sete medidas socioeducativas previstas, aquelas que privam ou restringem a liberdade do adolescente, como a internação ou semiliberdade devem ser aplicadas apenas em atos infracionais com violência ou grave ameaça à pessoa ou em caso de descumprimento de medida anterior. No entanto, a medida socioeducativa de internação tem sido aplicada com frequência em atos infracionais análogos ao tráfico de drogas e a crimes patrimoniais.

Já a medida de segurança será aplicada ao inimputável por doença mental na forma de uma internação em instituição hospitalar por tempo indeterminado, se a previsão

\footnotetext{
${ }^{2} \mathrm{Na}$ ótica do direito penal juvenil, há uma contradição nos sistemas de discernimento e de proteção justamente porque negam a culpabilidade, mas não renunciam à privação de liberdade, ainda que sob o pretexto de proteger ou de educar. Por isso, para Cillero Bruñol, o princípio de culpabilidade deve exercer a função, tanto no direito penal adulto como no sistema socioeducativo, de limite à intervenção estatal, mormente no caso de privação de liberdade. (CILLERO BRUÑOL, 2001, p. 71).
} 
legal da pena do crime for de reclusão. Se a pena prevista para o crime for de detenção, o código penal permite que a medida de segurança seja cumprida na forma de um tratamento ambulatorial. Inexistente a culpabilidade, o fundamento da intervenção do Estado na forma da medida de segurança será a periculosidade.

Como explicita Santos (2008, p. 25), a natureza da atribuição de culpabilidade e de periculosidade aos agentes possuem fundamentos diferentes, de acordo com o discurso oficial da teoria jurídica das medidas de segurança: “a relação culpabilidade/pena possui natureza subjetiva, mas a relação periculosidade criminal/medida de segurança possui natureza objetiva de proteção do autor (terapia) e da sociedade (neutralização) [...]" (SANTOS, 2008, p. 25). Essa ponderação reflete a finalidade real da internação manicomial, que é, para além da proteção, tratamento, e recuperação do indivíduo que se encontra sob a tutela do Estado (finalidade declarada da internação), a exclusão seletiva e, consequentemente, estigmatização do sujeito considerado "anormal".

\section{Periculosidade e medidas de segurança}

Conforme explicam Pavarini e Giamberardino (2012, p. 125-126), o Código Penal Brasileiro de 1940 reproduziu os termos adotados pelo legislador italiano em 1930 no que se refere à aproximação entre penas e medidas de segurança, sendo as primeiras cominadas porque "justas" e destinadas ao delinquente responsável, e as segundas, de natureza pessoal, impostas por serem "úteis", conforme finalidades de prevenção especial, tanto de neutralização como de ressocialização dos sujeitos tidos como perigosos.

Na legislação penal, porém, restou ausente a manifestação sobre o limite máximo do tempo de duração da medida de segurança, por conta de seu caráter fundado na biografia e em juízos de prognose. $\mathrm{O} \S 1^{\circ}$ do artigo 97 do Código Penal abre espaço para diferentes interpretações ao estabelecer apenas o prazo mínimo para a duração da internação manicomial e consolidar que esta será por tempo indeterminado. A internação por prazo indeterminado tem sido recentemente considerada inconstitucional, por violar a vedação às penas de caráter perpétuo. Sendo a medida de segurança muitas vezes mais grave do que a pena atribuída ao inimputável, e cuja finalidade de tratamento se mostrou historicamente falsa, como bem demonstra a criminologia crítica (CARVALHO, 2013, p. 508), deveria o inimputável ser beneficiado por todas as limitações existentes na aplicação tradicional das penas. A jurisprudência já vem consolidando o entendimento de 
que o limite da duração da medida de segurança deve ser dado pelo quantum de pena máxima cominada à infração penal, entendimento este que ensejou a publicação da Súmula $n^{\circ} 527$ deste tribunal. Ainda assim, é algo irrazoável e contraditório, conforme explicitamos em outro texto, entre outros motivos pelo fato de que, ainda assim, submete os inimputáveis a um tratamento mais gravoso do que aquele conferido aos imputáveis (BONGIORNO; BUDÓ, 2019).

Como notam Bustos Ramírez e Hormazábal Malarée (1999, p. 362, tradução livre), "a declaração de inimputabilidade implica em estabelecer maiores garantias ao sujeito, não diminuí-las". Essa dificuldade em compatibilizar garantias e direito penal de autor reflete o seu caráter intrinsecamente autoritário: "O fundamento do castigo no direito penal de autor é o próprio autor e as valorações abstratas que se possa fazer sobre esse autor. Assim, será castigado porque é perigoso, ou é traidor, ou imoral, de uma etnia diferente, etc." (BUSTOS RAMÍREZ; HORMAZÁBAL MALARÉE, 1999, p. 312). E é nesse direito penal de autor que reside a medida de segurança por tempo indeterminado. Para Pavarini e Giamberardino (2012, p. 144), "O pressuposto da periculosidade social ou criminal é de natureza subjetiva, como é evidente, sempre vinculado a prognósticos sobre o comportamento do indivíduo". Por ter caráter subjetivo, associado ao comportamento humano, há autores e autoras que não reconhecem o conceito de periculosidade como elemento essencial para se determinar ou não a internação, sobretudo baseados em seu caráter preditivo do futuro a partir do conhecimento da personalidade de um autor no passado. É o que defendem Pavarini e Giamberardino (2012, p. 145): "a denominada 'prognose criminal' nada tem de científica, mas se rege unicamente pela capacidade intuitiva do juiz, carregando toda a arbitrariedade que isso pode determinar (e objetivamente determina)".

Em virtude da atribuição de periculosidade ao agente inimputável, este depende de perícias médicas durante o período de internação para que se ateste a cessação dessa condição e se torne possível sua saída do hospital de custódia. Nessa fase de institucionalização entram em cena os saberes técnicos, que têm o poder de decidir sobre a cessação ou não da medida. Ao juiz fica reservada a atribuição de extrair as consequências jurídicas dos laudos psiquiátricos, definindo a libertação ou a manutenção da privação da liberdade. Como observa Foucault, isso faz com que a sentença que parte dessas perícias "[...] implique mais ou menos obscuramente em juízos de normalidade, atribuições de causalidade, apreciações de eventuais mudanças, previsões sobre o futuro 
dos delinquentes" (FOUCAULT, 2009).

\title{
Decisões judiciais sobre "cessação da periculosidade" e a apropriação dos
}

\section{saberes psi}

Na contramão da Lei de Reforma Psiquiátrica (Lei 10.216/2001), o Judiciário tem atuado em uma perspectiva institucionalizadora, ao invés de ler de forma mais complexa o conjunto das normas que regulam os direitos das pessoas com transtornos mentais (CARVALHO; WEIGERT, 2003). Em um estudo realizado em decisões do Superior Tribunal de Justiça ${ }^{3}$, apresentadas durante 0 mini-curso, chegamos às seguintes conclusões:

\begin{abstract}
Ainda que a legislação federal tenha concretizado avanços e dispensado atenção aos portadores de sofrimento mental, não se pode afirmar que esse avanço tenha provocado efeitos na esfera penal. Essa constatação é possível ante a análise jurisprudencial realizada, na qual pôde ser visualizada a dificuldade de inserção, pelos órgãos do Judiciário, dos elementos constantes na Lei 10.216/2001 nas decisões. Se, por um lado, alguns dos julgados mencionaram a referida Lei, por outro lado isso somente ocorreu quando estavam presentes violações evidentes da própria lei penal ou a jurisprudência consolidada do STJ, como na prisão de inimputáveis em presídios comuns ou no excesso de prazo no cumprimento da medida. Em casos nos quais se invocou o princípio da isonomia para garantir o reconhecimento do princípio da insignificância, o cumprimento da pena em concreto, ou a possibilidade de tratamento ambulatorial em casos de condutas apenadas com reclusão, jamais houve menção à Lei 10.216/2001. Pelo contrário, sobrepõe-se o tradicional discurso positivista da periculosidade, derivada mais dos fatos passados do que de qualquer possibilidade de prognose, até porque em muitos casos não sustentada sequer em laudos psiquiátricos (BONGIORNO, BUDÓ, 2019, p. 55).
\end{abstract}

A noção de periculosidade que norteia as medidas de segurança, e a institucionalização como principal resposta estatal à identificação do sujeito como um risco à sociedade implica, assim, em uma crítica estrutural à própria constitucionalidade de tais medidas, sendo necessária uma maior conformidade da norma penal e da prática judicial à Lei 10.216/2001.

\section{Inimputabilidade, vulnerabilidade e medidas socioeducativas}

A inimputabilidade pela menoridade tem um histórico bastante semelhante àquele exposto sobre as pessoas com transtornos mentais. Também aqui, a intervenção estatal diante da prática de uma infração por um adolescente não poderá declaradamente ser

\footnotetext{
${ }^{3}$ A pesquisa foi resultado de uma orientação do trabalho de conclusão de curso de Marina Bongiorno. $O$ trabalho, após revisado e com a contribuição da professora orientadora foi publicado (BONGIORNO; BUDÓ, 2019).
} 
punitiva, mas sim uma medida socioeducativa. Como no caso das medidas de segurança, as medidas socioeducativas são atravessadas por debates a respeito de sua natureza sancionatória, tendo em vista a sua semelhança com as prisões no Brasil. Não poderemos discorrer de forma aprofundada sobre como a solução encontrada pelo ECA vem precedida de um histórico de constantes e profundas violações de direitos de crianças e adolescentes no âmbito das instituições de internação. Mas é interessante observar especificamente o pressuposto da aplicação da medida pelo Estado: de forma declarada, a medida de internação busca a responsabilização infracional do adolescente e a sua inclusão em um programa individual socioeducativo; de forma real, é evidenciada a seletividade na definição sobre quem são os adolescentes que devem receber esse tipo de medida mais gravosa. Essa seletividade é construída a partir de uma série de preconcepções atravessadas pelas estruturas de raça, classe, gênero, etnia etc., que julgam suas famílias, e a capacidade que pais e mães possuem de educar os seus próprios filhos.

Essas decisões pela internação vêm carregadas de intervenções de diversos saberes, especialmente os saberes psi. Juízes têm requisitado constantes avaliações psiquiátricas de adolescentes que cumprem medidas socioeducativas para averiguar seu grau de periculosidade ou diagnosticar transtornos de personalidade antissocial (VICENTIN et al., 2010). A patologização dos adolescentes autores de ato infracional é tratada por Vicentin et. al. como "fenômeno analisador de determinadas lógicas de poder em jogo hoje na gestão dos riscos que a juventude coloca ao campo social, principalmente pela via da articulação entre transtorno mental e criminalidade juvenil" (VICENTIN et al., 2010, p. 62). As autoras demonstram que na esfera da infância e juventude, em especial em sua relação com o Poder Judiciário, tem-se um retorno ao período anterior às conquistas de desinstitucionalização do movimento antimanicomial, chegando-se ao ponto de, em São Paulo, por exemplo, um novo manicômio ser construído para abrigar adolescentes considerados perigosos ${ }^{4}$.

\footnotetext{
${ }^{4}$ A psiquiatrização do tratamento da juventude, entendida como "a predominância dos saberes e fazeres $p s i$ na gestão das problematizações e dos conflitos que setores da juventude vêm colocando ao campo social", pode ser identificada em alguns traços: 1) propostas de alteração do ECA centradas no argumento periculosidade e dos transtornos mentais e a criação de medidas de segurança para adolescentes; 2) crescente encaminhamento de adolescentes pelo juiz para avaliações psiquiátricas; 3 ) crescente internação psiquiátrica de adolescentes por determinação judicial e por prazos superiores àqueles que ingressam sem esse tipo de decisão, em casos de distúrbios de conduta e não psicóticos; 4) a fundação, no estado de São Paulo, da Unidade Experimental de Saúde (UES), em dezembro de 2006, destinada a oferecer atendimento para autores de ato infracional com diagnóstico de transtorno de personalidade e/ou de periculosidade, durante cumprimento de medida socioeducativa de internação e tiveram essa medida convertida pelo Poder
} 
A partir de São Paulo vem ocorrendo uma remanicomialização destinada aos adolescentes perigosos, os quais já cumpriram a medida socioeducativa e são internados sem que tenham cometido novo ato infracional ou crime. A partir da chave do transtorno de personalidade e de seu correlato, a periculosidade, o adolescente que precisa ser liberado compulsoriamente, em razão de haver completado 21 anos ou de ter cumprido os três anos de internação, é interditado civilmente por iniciativa do Ministério Público e é imposta a sua internação psiquiátrica por tempo indeterminado (FRASSETTO, 2011). Sequer prazos de reavaliação do caso, ou a definição de equipes incumbidas de promovê-la estão previstas, de modo que a característica que se sobressai desses processos de interdição é a absoluta indeterminação do tempo de privação de liberdade. Analisamos uma decisão nesse sentido, no mini-curso, e o estudo completo sobre o tema em um caso de grande repercussão midiática pode ser lido em Budó (2015).

Como observa Rauter (2003, p. 13), o transtorno antissocial possui uma característica em comum com o que se entendia antes por psicopatia: "o de pretender fazer da oposição às leis, da rebeldia, da desobediência, o sintoma de uma doença”. Não se trata, portanto, de algo diverso das tentativas positivistas de enquadrar o criminoso em algum tipo de anormalidade, trazendo como resposta à sua biografia e estilo de vida, e não aos seus atos, um tratamento correspondente. A característica inovadora é a do expansionismo que vem vivenciando a moderna psiquiatria simbolizada no transtorno antissocial, "pois se refere a estranhas formas de loucura lúcida, difíceis de diferenciar da normalidade", constituindo-se em um híbrido, segundo Rauter (2003), situado a meio caminho entre justiça e psiquiatria. Trata-se, de fato, da utilização pelo Estado de uma arma oferecida pela psiquiatria, descoberta no Brasil já no início do século XX: "a possibilidade da exclusão de cidadãos que não tenham contrariado qualquer artigo do Código Penal" (RAUTER, 2003, p. 43) ${ }^{5}$.

A patologização da juventude é entendida como uma estratégia por Rosa e

Judiciário em medida protetiva, com a justificativa de o SUS não atender tais casos em regime de contenção. (VICENTIN et al., 2010)

${ }^{5}$ Como observa Foucault, o "biográfico" faz existir o "criminoso" antes do crime e, num raciocínio -limite, fora deste: "Entramos então no dédalo "criminológico" de que estamos bem longe de ter saído hoje em dia: qualquer causa que, como determinação, só pode diminuir a responsabilidade, marca o autor da infração com uma criminalidade ainda mais temível e que exige medidas penitenciárias ainda mais estritas. À medida que a biografia do criminoso acompanha na prática penal a análise das circunstâncias, quando se trata de medir o crime, vemos os discursos penal e psiquiátrico confundirem suas fronteiras; e aí, em seu ponto de junção, forma-se aquela noção de indivíduo "perigoso" que permite estabelecer uma rede de causalidade na escala de uma biografia inteira e estabelecer um veredicto de punição-correção" (FOUCAULT, 2009. p. 239). 
Vicentin, advinda da adoção de uma postura de defesa social, despreocupada com os seus direitos e, sobretudo, tendente a excluí-los da vivência social. Para as autoras, a questão da periculosidade, da maneira como é percebida hoje no discurso político-jurídico-médico sobre o adolescente, já não a identifica como em sua origem oitocentista como um atributo intrínseco do sujeito, voltando-se para uma noção de "incontrolabilidade". Facilita-se, assim o seu uso, inclusive seu diagnóstico por parte dos juristas, os quais necessitam apenas verificar o comportamento indisciplinado do adolescente para entendê-lo como perigoso (ROSA; VICENTIN, 2010).

Porém, a expressão "periculosidade" tem desaparecido em parte das decisões que se referem ao cotidiano do Judiciário sobre as medidas socioeducativas, apesar de o biográfico permanecer. Em um estudo realizado em decisões do Superior Tribunal de Justiça, identificamos que a expressão periculosidade tem sido substituída pelo conceito de vulnerabilidade, como ensejadora das medidas socioeducativas mais gravosas. Trabalhamos com essas decisões no mini-curso, e me atenho aqui a colar os principais resultados, conforme a publicação:

\begin{abstract}
Quanto à palavra vulnerabilidade, objeto desta pesquisa, nota-se que ela foi empregada sempre em conjunto com a análise das condições pessoais e sociais do adolescente para determinar a medida socioeducativa ou protetiva mais adequada nas seguintes situações: 1) condição econômica desfavorável; 2) família desestruturada; 3 ) perda do pai ou da mãe; 4) influência negativa de membros da família; 5) prática de outros atos infracionais; 6) gravidez; 7) uso de entorpecentes; 8) dificuldade de cumprir normas e regras 9 ) identidade com a vida nas ruas; 10) abandono da escola; 11) más companhias; 12) pai e/ou mãe presos. Essas situações costumam ser apresentadas em conjunto, dependendo do caso do adolescente em questão e do que se está buscando fundamentar ao utilizar o termo vulnerabilidade. Em algumas situações, lê-se que o adolescente está em risco por conta dessa vulnerabilidade. Risco, por exemplo, de ser vítima de alguma agressão ou mesmo de passar fome ou necessidades. Em outras situações, especialmente quando ligada ao uso de drogas, à prática de outros atos infracionais e às más companhias, a vulnerabilidade parece ser entendida como propensão ao crime. Trata-se de uma estreita relação com o conceito de periculosidade: ao analisar a vida pregressa do indivíduo, faz-se uma projeção do que será o seu futuro. Confirma-se aí a passagem linearmente compreendida do menor em perigo, em decorrência de suas condições sociais, ao menor perigoso: de vítima da sociedade desigual e de pais irresponsáveis a algoz dessa mesma sociedade (BUDÓ; KIRCH, 2020).
\end{abstract}

Nota-se, assim, que outra vez o biográfico é acionado como forma de reprovação do sujeito, a partir, evidentemente das estruturas de poder que conduzem algumas pessoas à total vulnerabilização de seus direitos e outras à posição de julgar. A racialização dos corpos de quem é julgado e a dificuldade de percepção do lugar das estruturas de opressão nessa delimitação de um direito penal/direito infracional de autor 
também impedem uma compreensão crítica estrutural do funcionamento das interações entre os saberes psi e o direito.

\section{Conclusão}

As interações dos saberes psi com o direito são inúmeras, e, no campo penal, remetem a um histórico de segregação, violação de direitos e arbitrariedade. A inimputabilidade não tem sido tratada como uma forma de afastar as sanções penais, mas sim de aplicar outras que, muitas vezes, são mais graves do que aquelas impostas aos imputáveis, especialmente em razão dos fundamentos de um direito penal de autor. $\mathrm{O}$ direito penal de autor fundamenta a intervenção estatal na noção de risco social, de periculosidade, e, das mais diversas formas, é assim que adolescentes e pessoas com transtornos psíquicos têm sido submetidos, de forma grave e violadora às "medidas" a eles impostas. Para a superação dessa perspectiva biográfica que criminaliza sujeitos por serem quem são, provirem de onde provém e parecerem como parecem é fundamental a interdisciplinaridade em pressupostos teóricos e políticos emancipatórios, para que o horror vivenciado no interior das instituições torne-se apenas mais uma história de atrocidades passadas a serem contada no futuro.

\section{Referências}

BONGIORNO, Marina; BUDÓ, Marília de Nardin. Cidadãos de Segunda Categoria: O Sofrimento Mental nas Decisões do Superior Tribunal de Justiça Sobre as Medidas de Segurança. Revista Direitos humanos e Democracia, ano 7, n 13, 2019.

BUDÓ, Marília de Nardin. Do anormal ao perigoso: a psiquiatrização da medida socioeducativa de internação e a prisão perpétua à brasileira. Revista de Estudos Criminais, v.57, p.69- 98, 2015.

BUDÓ, Marília de Nardin; KIRCH, Aline. Vulnerabilidade e seletividade: uma revisita às decisões sobre privação de liberdade de adolescentes no STJ (2010-2020) In: Direitos Humanos e Vulnerabilidades. Florianópolis: Habitus, 2020, v.1, p. 211-234.

BUSTOS RAMÍREZ, J. J.; HORMAZÁBAL MALARÉE, H. Lecciones de derecho penal. Madrid: Trotta, 1999. V. II.

CARVALHO, Salo de. Pena e medidas de segurança no direito penal brasileiro. São Paulo: Saraiva, 2013.

CARVALHO, Salo; WEIGERT, Mariana. A punição do sofrimento psíquico no Brasil:

Reflexões sobre os impactos da Reforma Psiquiátrica no Sistema de Responsabilização Penal. Revista de Estudos Criminais, n. 48, p. 55-90, jan./mar. 2013.

CILLERO BRUÑOL, Miguel. Nulla poena sine culpa: un límite necesario al castigo penal.In: UNICEF. Justicia y derechos del niño, n. 3.Buenos Aires: 2001. p. 65-76.

FOUCAULT, Michel. Vigiar e punir: nascimento da prisão. Tradução de Raquel Ramalhete. 37 ed. Petrópolis: Vozes, 2009.

FRASSETO, Flávio Américo. Fronteiras psi-jurídicas dos casos de interdição em andamento em São Paulo e a questão da Unidade Experimental de Saúde. In: Políticas 
de saúde mental e juventude nas fronteiras psi-jurídicas. São Paulo: Conselho Regional de Psicologia da $6^{a}$ Região, 2011. p. 9-14.

PAVARINI, M.; GIAMBERARDINO, A. Teoria da pena e execução penal: uma introdução crítica. 2. ed. Rio de Janeiro: Lumen Juris, 2012.

RAUTER, Cristina. Criminologia e subjetividade no Brasil. Rio de Janeiro: Revan/ICC, 2003.

ROSA, Miriam Debieux; VICENTIN, Maria Cristina. Os Intratáveis: o exílio do adolescente do laço social pelas noções de periculosidade e irrecuperalidade. Psicologia Política, 10(19), 107-124, 2010.

ROXIN, Claus. La teoría del delito en la discusión actual. Traducción de Manuel Abanto Vásquez. Lima: Grijley, 2007.

SANTOS, Juarez Cirino. Direito penal: parte geral. 3 ed. Rio de Janeiro: Lumen Juris/ICPC, 2008.

SILVA, Luana de Carvalho. O princípio da culpabilidade e a produção dos sujeitos. Programa de Pós-graduação em Direito da Universidade Federal do Paraná. Dissertação (mestrado). 196 f. Curitiba, 2008.

VICENTIN, Maria Cristina G.; GRAMKOW, Gabriela; ROSA, Miriam Debieux. A patologização do jovem autor de ato infracional e a emergência de "novos" manicômios judiciários. Revista Brasileira Crescimento e Desenvolvimento Humano, v. 20, n. 1, p. 61-69, 2010.

ZAFFARONI, Eugenio Raúl; BATISTA, Nilo; ALAGIA, Alejandro; SLOKAR, Alejandro. Direito Penal Brasileiro, v. II,I. Rio de Janeiro: Revan, 2010. p. 65.

ZAFFARONI, Eugenio Raúl; PIERANGELI, José Henrique. Manual de direito penal brasileiro. v. 1.7 ed. São Paulo: Revista dos Tribunais, 2008. 